\title{
MINIMALISMO EM UM ENFOQUE PSICOLINGUÍSTICO: OS PRINCÍPIOS DE LIGAÇÃO E SUA ATUAÇÃO NO PROCESSAMENTO ON-LINE DA CORREFERÊNCIA
}

\author{
José Ferrari Neto \\ Débora Vasconcelos Correia
}

\begin{abstract}
RESUMO
Este artigo visa avaliar o quanto um modelo formal de gramática pode ser aplicado aos processos mentais on-line envolvidos no processamento sentencial. Para tanto, elaborou-se um experimento em que se observou como os Princípios de Ligaçáo atuam no processamento da correferência em Português Brasileiro (PB). Os resultados sugerem uma convergência entre computação linguística e teorias de processamento linguístico.
\end{abstract}

PALAVRAS-CHAVE: correferência; Princípios de Ligação; processamento linguístico.

\section{Introdução}

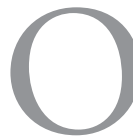

estudo da linguagem enquanto componente da mente humana (portanto, fazendo parte das capacidades cognitivas da espécie) é feito atualmente a partir de duas grandes perspectivas. Em uma, busca-se a elaboração de construtos formais (teóricos) que funcionem como modelo do conhecimento linguístico internalizado de um falante. Em outra, o que se pretende é a elaboração de teorias que permitam a formulação e a verificação de hipóteses sobre como esse conhecimento linguístico é posto em uso por meio de suas interfaces com os sistemas de produção e de compreensão da linguagem. A primeira perspectiva é típica de correntes formalistas, entre as quais o 
gerativismo, enquanto a segunda é característica das correntes de estudos em Psicolinguística, em especial a Psicolinguística Experimental.

Embora haja uma nítida convergência entre ambas as abordagens, no sentido de que elas assumem, cada uma a seu modo, uma concepção de língua de base mental, internalista e cognitiva, o fato é que as duas correntes têm se desenvolvido de forma relativamente autônoma (CORRÊA, 2005, p. 02). Uma tentativa de aproximação tem ocorrido, a partir do Programa Minimalista (CHOMSKY, 1993), mas alguns passos a mais na direção da convergência ainda se fazem precisos. Uma maior quantidade de evidências empíricas acerca dos processos mentais envolvidos na produção e compreensão de linguagem pode ajudar a sustentar uma explicação de fenômenos linguísticos de base notadamente formal, com ambas as perspectivas alimentando-se mutuamente.

Nesse sentido, o estudo da atuaçáo dos princípios de ligação (Binding Principles) no processamento se afigura como um interessante fenômeno a ser investigado por essa perspectiva mais integrada entre Linguística e Psicolinguística. Isso porque, sendo tais princípios formulados no âmbito de uma teoria de língua, e, portanto, tendo de satisfazer a requisitos de adequação descritiva e explicativa, podem igualmente ser analisados como condiçóes de interface a serem satisfeitas. Daí poder-se pressupor que há uma interação entre princípios formais e fatores de processamento, na medida em que a atuação dos primeiros é em boa parte determinada pelos segundos, o que leva a se avaliar o quanto tais princípios devem ser propostos considerando-se o modo como são processados pelo aparato linguístico.

Dessa forma, este trabalho tem por objetivo avaliar o quanto construtos teóricos propostos pela teoria linguística, em especial a gerativa, para dar conta da computaçáo envolvida na derivação de sentenças podem ser estendidos aos processos mentais on-line envolvidos no processamento sentencial. Em especial, procura-se aqui observar como os Princípios de Ligação atuam no processamento on-line de relaçóes correferenciais em Português Brasileiro (PB). Pretende-se que os dados aqui coligidos possam prover evidências empíricas tanto acerca do modo como podem ser compreendidos estes princípios a partir da ótica do processamento correferencial quanto a respeito de como modelos formais de língua podem ser tomados como modelos de processamento.

O trabalho está organizado da forma como se segue. Na seção seguinte, apresenta-se o fenômeno da correferência intrassentencial, bem como os prin- 
cípios que foram propostos para explicar os contextos sintáticos que permitem o estabelecimento das relaçóes correrefenciais no escopo da sentença. Na seção 3 discute-se a questão da atuação desses princípios quando do processamento da sentença por um falante de $\mathrm{PB}$, mostrando como a questão é tratada do ponto de vista dos modelos formais da Linguística de orientação gerativista e do ponto de vista de teorias de processamento da linguagem propostas no âmbito da Psicolinguística Experimental. Na seção 4, por sua vez, apresentam-se os pontos fundamentais da pesquisa a ser aqui conduzida, preparando terreno para a apresentação do experimento aplicado e discussão dos resultados, já na seção 5 . Na seção 6 tratam-se das consideraçóes finais.

\section{Correferência e princípios de ligação}

Chama-se correferência ao fenômeno no qual dois elementos linguísticos referem-se um ao outro no interior de um enunciado e ambos remetem ao mesmo ser ou coisa do universo extralinguísticos. Em um texto ou sentença, esses elementos podem organizar-se de forma que possa ocorrer ou uma antecipação da referência (ou seja, que um dos elementos indique que fará referência a outro ainda não presente no enunciado) ou uma retomada da referência (ou seja, que um dos elementos indique que fará referência a um elemento já citado no enunciado). Ao primeiro tipo, denomina-se correferência catafórica, e, ao segundo, correferência anafórica. Nessa última, o elemento que é retomado recebe o nome de antecedente, e o elemento que o retoma é denominado retomada anafórica.

$\mathrm{Na}$ teoria linguística de orientação gerativista, o estudo das relações correferenciais, em especial a correferência anafórica, tem sido o objeto de estudo de um módulo específico, a Teoria da Ligação (Binding Theory). Nela, tem-se buscado, basicamente, a determinação dos fatores sintáticos que regem o estabelecimento de relaçóes correferenciais, por meio da formulaçáo de princípios formais concernentes a cada tipo de retomada considerado pela teoria, a saber, as anáforas, os pronomes e as expressóes referenciais. Cumpre dizer que tais princípios são atinentes ao funcionamento dessas formas de retomada apenas quando inseridas em um contexto sentencial, não indo além dos limites da sentença, o que implica afirmar que os princípios de ligação se aplicam aos casos de correferência intrassentencial, mas não se estendem aos casos em que 
a correferência se estabelece para além da frase, já no nível do texto/discurso (cf. LEITÁO \& MELO, 2011, p.03).

De acordo com a Teoria da Ligação, anáforas são os elementos de valor reflexivo ou recíproco, possuindo distribuição oposta a dos pronomes, definidos como elementos de valor puramente referencial. Já as expressões- $\mathrm{R}$ são os constituintes sintagmáticos (DP's e NP's) que se referem a uma entidade no mundo extralinguísticos. Cada uma dessas formas apresenta características distribucionais específicas, e para cada uma delas foi proposto um princípio formal, que rege as condiçôes mediante as quais seus usos são licenciados. Em sua formulação inicial (CHOMSKY, 1981), a Teoria da Ligação propunha os seguintes conceitos:

\section{I - Ligação}

A liga $B$ sse:

i. A e B estão coindexados;

ii. A c-comanda B estão coindexados

A primeira alínea da ideia acima sobre a ligação é atinente ao fato de, na correferência, dois elementos terem necessariamente de ter o mesmo índice referencial. Essa exigência é livre de restriçôes de ordem estrutural (sintática) e responde em boa medida pelos casos de correferência que se dão em níveis para além do sentencial. Mas, para a ligação, é preciso que haja ao menos um fator de ordem sintática, o que é dado justamente pela noção de c-comando, na forma como exposto na segunda alínea acima. Dessa forma, é possível haver elementos correferenciais náo ligados, ainda que para haver ligação seja mister haver correferência. As frases seguintes ilustram essa afirmação:

(a) A equipe $e_{i}$ jogou muito mal, mas a torcida aplaudiu o time mesmo $_{i}$ assim.

(mesmo índice referencial, mas sem c-comando)

(b) Paulo aposta em si mesmo ${ }_{i}$ para ganhar o prêmio. (mesmo índice referencial, mas com c-comando)

Em (a) há a correferência, mas não a ligação, e em (b) há correferência e ligação. Portanto, a ligação é um caso de correferência, embora nem toda correferência seja ligação. 
A noção de c-comando é, como se vê, fundamental para a caracterização da correferência intrassentencial que se dá entre elementos ligados na sentença. O entendimento da noção de c-comando envolve a compreensão da noção de dominância. Essas noções podem ser definidas na forma como se segue:

II - Dominância

Um nó A domina $B$ sse:

(i) A é mais alto que B;

(ii) É possível traçar uma linha direta de A até B;

III - C-comando

Um nó A c-comanda um nó B sse:

i. A não domina $\mathrm{B}$;

ii. B não domina $A$;

iii. o primeiro nó ramificado que domina $\mathrm{A}$ também domina $\mathrm{B}$

A articulação entre os conceitos mencionados permitiu a caracterização dos contextos sintáticos nos quais seriam licenciadas construçốes gramaticais envolvendo anáforas, pronomes e expressóes- $\mathrm{R}$ e seus respectivos antecedentes. Daí a formulação de princípios universais que expressassem esses contextos em um modelo formal de gramática, que se constituiu no cerne da Teoria da Ligação. Esses princípios, propostos respectivamente para cada um tipo de elemento correferencial (anáfora, pronome e expressões-R), são os seguintes:

PRINCÍPIO A

Uma anáfora deve ser ligada em seu domínio de vinculação

PRINCÍPIO B

Um pronome deve ser livre em seu domínio de vinculação

\section{PRINCÍPIO C}

Uma expressão-R deve ser livre em qualquer domínio

Os princípios de ligação são particularmente poderosos para explicar a gramaticalidade ou a agramaticalidade de certas sentenças. Isso significa que, 
levando-se em conta somente as adequaçóes explicativa e descritiva do modelo formal de língua em que se acham inseridos, é mister reconhecer sua pertinência. Entretanto, isso não impede o surgimento de questóes a respeito da maneira como eles atuam no comportamento ordinário da linguagem. Essas questôes são concernentes ao modelo formal tomado em si mesmo, em seus aspectos explicativos e descritivos, quanto à maneira como eles interagem com as interfaces que sustentam a linguagem humana. A seção a seguir busca apresentar uma caracterização dessas questóes, sob as óticas linguística e psicolinguística, respectivamente.

\section{Perspectivas linguística e psicolinguística acerca dos princí- pios de ligação e seu processamento}

Posteriormente, com a evolução dos modelos formais propostos pela Teoria Linguística de orientação gerativista, novas descriçôes do modo de funcionamento dos princípios de ligação no curso das computaçóes linguísticas envolvidas na geração de sentenças foram propostas. No Programa Minimalista (CHOMSKY, 1993), modelo mais recente do gerativismo, os Princípios de Ligação, ainda que não tenham sofrido modificações significativas em relação às formulaçóes iniciais, suscitaram novas questôes, as quais tangem, especialmente, às relaçôes entre o modelo formal de língua e as interfaces que lhes dão suporte. Nesse sentido, houve uma maior aproximação entre a concepção teórica de gramática e o modo como esta é implementada pelo aparato orgânico humano dedicado à linguagem. Isso levou à formulação de mais conjecturas acerca da relação entre os processos computacionais envolvidos na derivação de sentenças, na forma como explicitada no Programa Minimalista, e o processamento linguísticos on-line, isto é, os processos mentais subjacentes à produção e à compreensão de sentenças.

Assim, no Minimalismo, uma das questóes fundamentais em relação aos princípios de ligação foi a determinação do momento em que eles atuariam. Em outras palavras, tratava-se de apontar em que ponto do curso da derivação linguística formalmente definida pelo modelo teórico os princípios agiriam, licenciando a sentença ou fazendo a derivação fracassar. No modelo precedente ao Minimalismo, o Modelo de Princípios e Parâmetros (CHOMSKY, 1981), foi proposto que os princípios atuariam na estrutura profunda (Deep 
Structure), um nível de interface entre a língua e os sistemas conceptuais-intencionais. Por outro lado, atualmente, no Minimalismo, sugere-se que eles se aplicam na Forma Lógica (Logical Form) (HORNSTEIN, NUNES; GROHMANN, 2005). Uma visão alternativa (FERREIRA, 2000) postula que os princípios agem após a Forma Lógica, já na interface Conceptual-Intencional (C-I Interface), sendo que sua violação não acarreta bloqueio (crash) da computação linguística. Como se percebe, a questão do ponto exato de atuação dos princípios permanece em aberto atualmente, e novas evidências empíricas a respeito ainda estão para ser aduzidas.

Pode-se dizer que a caracterização referida traduz a perspectiva linguística a respeito da ação dos princípios de ligação no curso temporal da computação linguística envolvida na derivação de sentenças em uma língua. Nela, a consideração das relaçóes entre os passos derivacionais previstos no modelo e sua implementação em sistemas de desempenho, ainda que prevista (ao menos no Minimalismo), não é formalmente caracterizada. Uma perspectiva que levasse essa relação em conta no tratamento da questão empírica da atuaçáo dos princípios de ligação, durante o momento reflexo do processamento de sentenças, descreveria o papel deles em termos da sua interação com os meios físicos que subjazem ao processamento linguísticos online. Nessa orientação, a análise dos fatores ligados à memória de trabalho, ao custo de processamento das diferentes formas de retomada anafórica e ao papel dos traços formais e semânticos no estabelecimento das relaçóes correferenciais são levados em conta na investigação acerca da aplicação dos princípios no momento em que uma sentença é ouvida por um falante. Isso configuraria a perspectiva psicolinguística a respeito dos princípios de ligação.

Essa perspectiva tem se aprofundado nas questóes decorrentes da adoção de uma concepção mais procedimental da atuação dos princípios de ligação, investigando, entre outros pontos, uma possível influência de elementos sentenciais que ficam armazenados na memória de trabalho, à medida que a sentença é lida ou ouvida, e que podem, em momentos posteriores do processamento sentencial, atuar como possíveis antecedentes para elementos anafóricos que são identificados enquanto uma sentença é processada. No momento em que um elemento anafórico é identificado em uma dada configuração sintática, os princípios de ligação seriam acionados e buscariam, na memória de trabalho, os possíveis antecedentes com os quais esse elemento 
anafórico poderia vincular-se. Se esse elemento estiver sob o escopo de atuação de um dado princípio, diz-se que ele é um antecedente disponivel e, ao contrário, caso ele esteja fora desse escopo, será considerado um antecedente indisponivel.

A pesquisa psicolinguística tem buscado, portanto, determinar em que momento e em que ponto do processamento on-line os princípios de ligação atuariam, e os resultados experimentais obtidos até aqui permitem apontar três conclusôes. Uma visão sugere que os princípios atuam tão logo o parser (processador sintático) encontre a retomada e haja um antecedente disponível (NICOL \& SWINNEY, 1989, com dados do inglês; OLIVEIRA, LEITÃO \& HENRIQUE, 2012; OLIVEIRA, LEITÁO \& ARAÚJO, 2013, com dados do português brasileiro). Uma outra proposta afirma que a aplicação deles pode sofrer influência de antecedentes não disponíveis, o que aponta para uma não imediaticidade da ação dos princípios (BADECKER \& STRAUB, 2002). Uma proposta alternativa afirma que os princípios podem atuar logo no momento em que a retomada é processada, mas que pode haver violação dos mesmos em momentos posteriores do processamento (STURT, 2003; KENNISON, 2003).

Como se vê, a perspectiva psicolinguística não desconsidera de todo o modelo teórico no qual se apoiam os princípios de ligação, apenas busca fundamentá-la mais em pontos relativos à memória, à recuperação de informaçôes nela contidas e em fenômenos mais próximos do processamento real das sentenças. Por seu turno, a visão linguística também não se afasta tanto dos fatores ligados ao papel das interfaces no processo. Uma articulação mais próxima entre as duas perspectivas é, assim, viável, e será explorada na próxima seção.

\section{Articulação entre as perspectivas linguística e psicolinguística}

Combinando-se as perspectivas acima delineadas, pode-se formular a questão acerca do processamento dos princípios em termos que levem em conta tanto o modelo formal proposto no Minimalismo quanto o processamento on-line. Novamente, três hipóteses iniciais podem ser propostas. Se a aplicação dos princípios é imediata, entẫo eles se aplicarão tão logo ocorra um merge entre o constituinte que contém o antecedente e o constituinte que 
contém a retomada, o que jogaria a favor da proposta de Nicol \& Swinney (1989). Por outro lado, se a aplicação dos princípios se dá na Forma Lógica, ou seja, num momento após Spell-Out, então é preciso que a computação constitua toda uma estrutura interpretável no nível de interface antes da aplicação dos princípios, o que se conforma com a ideia de Badecker \& Straub (2002). Por fim, se a aplicação dos princípios se dá de imediato, mas pode ser violada em passos subsequentes da computação, então se deve assumir que os princípios atuam na interface, mas não forçam a derivação a fracassar, podendo a sentença ser interpretada posteriormente, como sugerem Kennison (2002) e Sturt (2002).

Uma possível maneira de se testarem essas possibilidades é a análise de como são processadas e interpretadas sentenças em que a retomada esteja dentro de um constituinte movido, como nas frases seguintes (extraídas de HORNSTEIN, NUNES \& GROHMANN, 2005, p. 312):

(1) John wondered [which picture of him $]_{t}$ Fred liked ${ }_{t}$.

(2) John wondered [which picture of himself $]_{t}$ Fred liked ${ }_{t}$.

Em frases como (1) e (2), os princípios podem se aplicar ou tấo logo o constituinte WH- seja adjungido à posição de argumento interno do verbo da oração encaixada, ou após o movimento (por cópia) do constituinte WHpara a posição de Spec, CP, o que faria com que houvesse duas posições possíveis para sua aplicação. Do ponto de vista do processamento, os princípios se aplicariam tão logo o parser chegasse a him ou a himself. De acordo com Hornstein, Nunes \& Grohmann (2005), a intepretação de him como correferente a Fred é agramatical em (1), e em (2) himself pode se referir a John ou Fred, o que torna a sentença ambígua. Assim, as questóes que surgem são a de saber qual o local/momento de aplicação dos princípios (o que poderia ser antes do movimento do constituinte WH- ou depois de seu movimento), e que outros fatores podem atuar na interpretação das relaçóes de correferência (possivelmente fatores semânticos e/ou contextuais, ou mesmo se os princípios seriam imunes a esses fatores). Para investigar essas questóes e prover mais evidências empíricas que fundamentem as possíveis respostas, formulou-se o experimento descrito a seguir. 


\section{Experimento}

O experimento aqui desenvolvido foi elaborado com vistas a investigar o papel dos princípios de ligação no processamento de elementos correferenciais, no caso, pronomes e anáforas, assumindo-se a caracterização tanto dos princípios quanto dos elementos estabelecida no Programa Minimalista (CHOMKSY, 1993). Buscou-se articular, em sua elaboração, as perspectivas linguística e psicolinguística, na forma como descritas nas seções anteriores. $\mathrm{O}$ objetivo geral foi o de testar a atuação on-line dos princípios no momento em que eles se estabelecem.

\section{Descrição do Experimento}

Paradigma Experimental: leitura automonitorada (Self-Paced Reading Task)

Variáveis Independentes: Tipo de Retomada (pronome x anáfora) e Tipo de Frase (leitura ambígua, leitura com o antecedente, leitura com o subsequente)

Variáveis Dependentes: Tipo de Resposta (antecedente, subsequente) e Tempo de leitura do segmento crítico

Design Experimental: fatorial 2x3, com quadrado latino

Sujeitos: 18 alunos de graduação da Universidade Federal da Paraíba, com idade média de 25,6 anos, todos falantes nativos de português brasileiro

Estímulos: Duas frases por condição, num total de 12 frases, mais 28 frases distratoras, totalizando 40 estímulos. Usou-se o software Paradigm, versão 2.0, para montagem, aplicação e registro dos dados, implementado em um notebook Dell Inspiron 142520

Condiçóes Experimentais:

\section{PLAN (pronome/leitura ambígua)}

João/perguntou/que desenho dele/Fred viu. De quem é o desenho?

\section{PLAT (pronome/leitura antecedente)}

João/perguntou/que irmã dele/Fred namorou. De quem é a irmã?

\section{PLSQ (pronome/leitura subsequente)}

João/perguntou/que dinheiro dele/Fred emprestou. De quem é o dinheiro? 


\section{ALAN (pronome/leitura ambígua)}

João/perguntou/que desenho dele mesmo/Fred viu. De quem é o desenho?

\section{ALAT (pronome/leitura antecedente)}

João/perguntou/que irmã dele mesmo/Fred namorou. De quem é a irmã?

\section{ALSQ (pronome/leitura subsequente)}

João/perguntou/que dinheiro dele mesmo/Fred emprestou. De quem é o dinheiro?

\section{Procedimento}

Conforme já dito, o experimento foi elaborado por meio do software $\mathrm{Pa}$ radigm, versão 2.0. e o paradigma experimental usado foi a da leitura automonitorada, na qual o participante controla o seu ritmo de leitura diante da tela do computador onde são mostrados os estímulos. $\mathrm{O}$ experimento em questão foi desenvolvido e aplicado no Laboratório de Processamento Linguístico (LAPROL), situado na Universidade Federal da Paraíba (UFPB), o que permitiu aos participantes voluntários a realização da tarefa experimental em um ambiente silencioso e de total concentração. A tarefa consistiu na leitura natural de frases divididas em quatro segmentos, ao término das quais havia uma pergunta de compreensão, a qual obrigava o participante a escolher como resposta ou o DP que indicava o antecedente ou o DP que indicava o subsequente, sempre em relação ao elemento correferencial situado em um dos segmentos. Essas respostas indicavam a interpretação dada pelo falante ao elemento correferencial, se referente ao antecedente ou ao subsequente, conforme ilustrado abaixo:

a) João/perguntou/que desenho dele/Fred viu. De quem é o desenho? 1234 (interpretação ambígua)

b) João/perguntou/que irmã dele/Fred namorou. De quem é a irmã? 1234 (interpretação preferencial com o antecedente)

c) João/perguntou/que dinheiro dele/Fred emprestou. De quem é o dinheiro?

1234

(interpretação preferencial com o subsequente) 
Os participantes sentaram-se em frente à tela do computador e leram as instruçóes do experimento. Nessas instruçóes, o participante era informado que na tela apareceriam frases segmentadas e, em seguida, uma pergunta de interpretação relacionada às frases lidas. Depois de ler as instruçóes, os participantes passaram por um teste prático a fim de habituá-los com o experimento. Todos os participantes foram instruídos a ler com atenção e da maneira mais natural possível. Para dar início ao experimento, o participante apertava a barra de espaço do teclado à sua frente para começar a leitura do primeiro segmento. Para dar continuidade à leitura dos próximos segmentos, os participantes deveriam pressionar a barra de espaço novamente até o último segmento. Após a leitura da última palavra da sentença, os participantes deveriam pressionar a barra de espaço mais uma vez e uma pergunta interpretativa sobre a sentença lida apareceria na tela do computador. Se a resposta de pergunta fosse, por exemplo, João, o participante pressionaria a tecla $S$ (relativa ao antecedente) do computador. Se a resposta fosse Fred, pressionaria a tecla L (relativa ao subsequente). Neste experimento, analisou-se o tempo médio de leitura do segmento que continha o elemento correferencial, chamado de segmento crítico, além do número de respostas à pergunta final. Com base nesses dados, foram feitas as análises estatísticas e elaborados os resultados deste experimento.

\section{Hipóteses e Previsóes:}

I - Os princípios se aplicam tão logo a retomada é processada (ou na posição para a qual o constituinte se moveu)

- Maior número de respostas relativas ao antecedente em todas as condições

II - Fatores Semânticos influem na interpretação da correferência (ou os princípios não são absolutos para a interpretação)

- Menor número de respostas relativas ao antecedente nas condiçóes PLSQ e ALSQ

- efeito principal de tipo de sentença

III - Pronomes e anáforas não possuem comportamento semelhante em relação ao processamento, sendo aqueles mais rápidos que aquelas - Efeito principal de tipo de retomada 
Resultados e Discussão

\section{Os resultados obtidos são mostrados a seguir. Gráfico 1}

\section{Tempo Médio de Leitura do Segmento Crítíco}

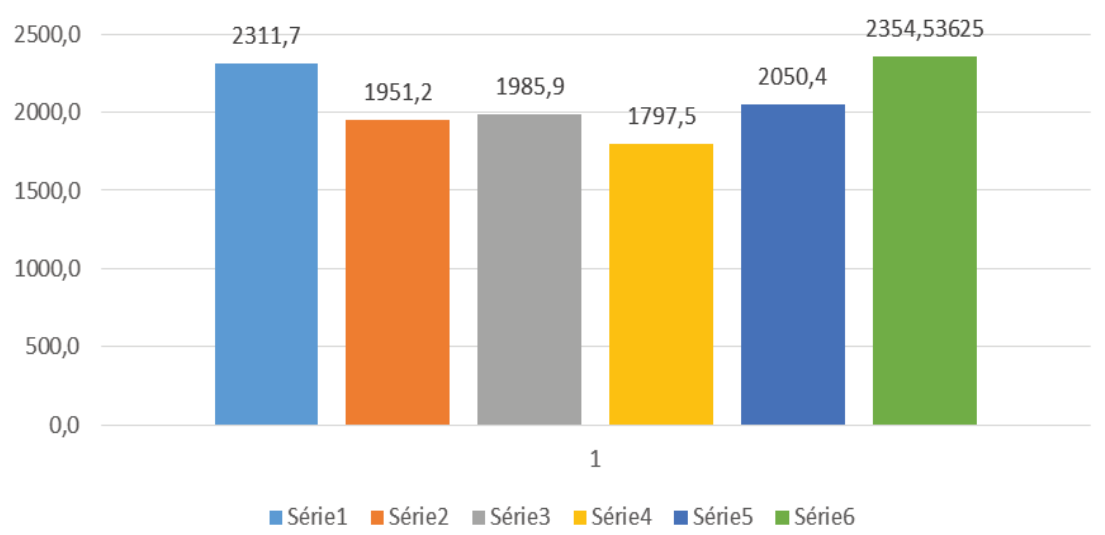

Os dados concernentes ao tempo de leitura do segmento crítico foram submetidos a uma análise de variância (two-way ANOVA) com design fatorial 2 (tipo de retomada) x 3 (tipo de frase), não sendo observado efeito principal de tipo de retomada $(\mathrm{F}(1,31)=0,011$ e $\mathrm{p}<0,91)$, indicando que pronomes e anáforas foram lidos no mesmo tempo, impondo assim cargas de processamento semelhantes, o que vai de encontro à hipótese assumida. Dessa forma, ainda que pronomes e anáforas tenham status diferentes dentro do modelo, no que diz respeito à sua distribuição e aos seus respectivos princípios, do ponto de vista do processamento, seu comportamento é igual. Daí possivelmente não haver diferenças quanto ao custo de processamento dos Princípios $\mathrm{A}$ e $\mathrm{B}$, quando comparados entre si. Também não se observou efeito significativo de tipo de frase $(\mathrm{F}(2,62)=0,659$ e $\mathrm{p}<0,52)$, sugerindo que são os princípios de ligação, tomados em si mesmos, que regem a interpretação preferencial dada aos elementos correferenciais, ainda que essa interpretação possa ser sensível a fatores semânticos, de acordo com a análise das respostas à pergunta final, a ser mostrada a seguir. Logo, fatores semânticos sozinhos não se constituem nos fatores decisivos para a interpretação, mas parecem 
agir conjuntamente com os fatores sintáticos. Por fim, registrou-se um efeito significativo de interação entre tipo de retomada e tipo de frase $(\mathrm{F}(2,62)=$ $4,58 \mathrm{p}<0,014)$, indicando que fatores semânticos afetam diferentemente o processamento do pronome e da anáfora, ou seja, que os princípios de ligação são diferentemente afetados por fatores semânticos. Pronomes são lidos mais lentamente em sentenças ambíguas, tendência essa que se reverte quando o elemento correferencial é uma anáfora, ao passo que essas, quando presentes em sentenças cuja interpretação preferencial é como vinculada ao antecedente ou ao subsequente, tendem a ser lidas mais lentamente, em oposição aos pronomes, que tendem a ser lidos mais rapidamente. Portanto, ainda que, quando tomadas em isolado, as diferentes formas de correferência, no caso, pronomes e anáforas, não apresentem discrepâncias quanto ao seu custo de processamento, ao se levar em conta o contexto em que se inserem, passam a apresentar diferenças, o que sugere demandas procedimentais específicas. $\mathrm{O}$ gráfico seguinte ilustra essas afirmaçóes.

\section{Gráfico 2}

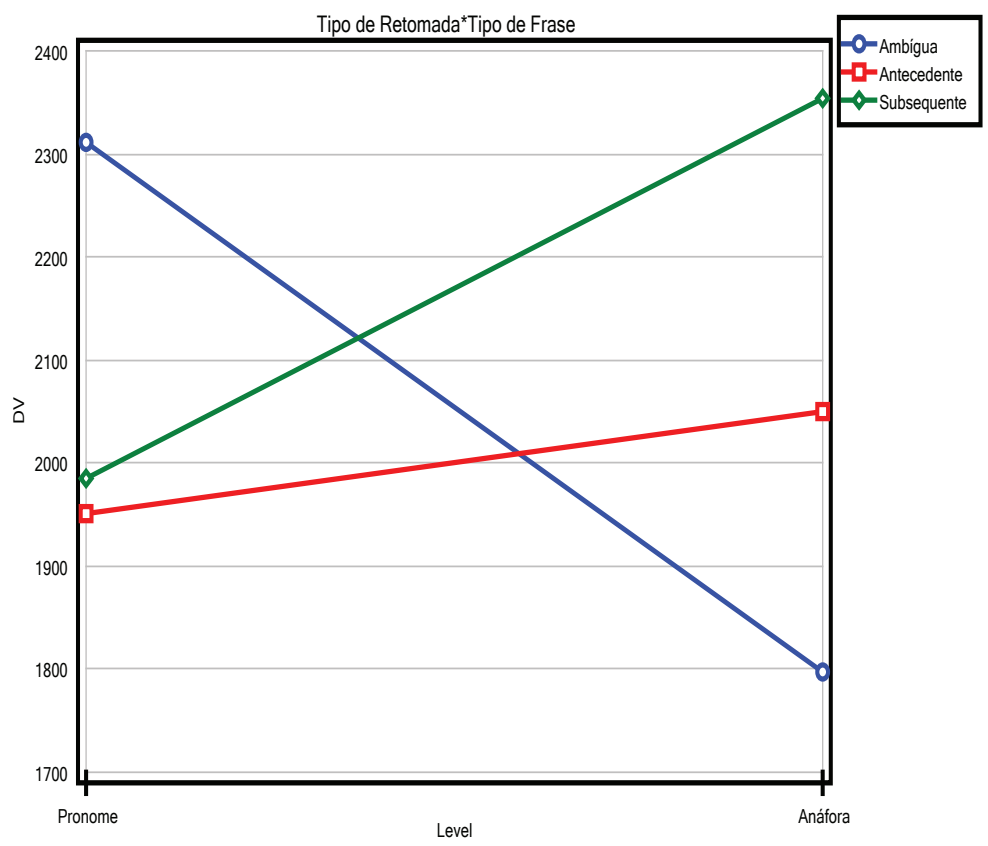


Já a análise das respostas à pergunta final aparece nos gráficos seguintes:

\section{Gráfico 3}

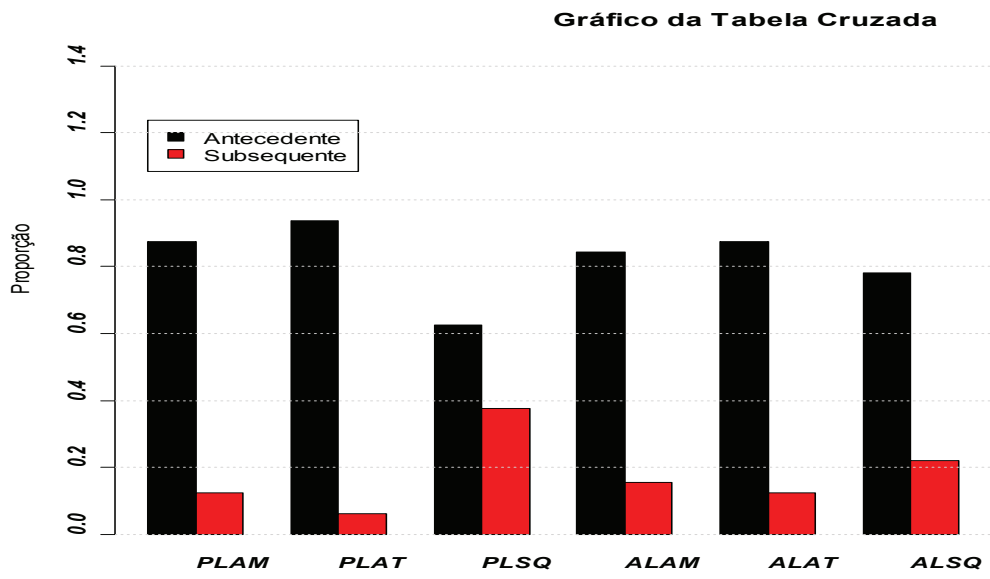

O que o gráfico 3 indica é que a preferência pela vinculação ao antecedente ocorreu em todas as condiçóes experimentais, o que é confirmado por uma análise de qui-quadrado (chi-square test), que apontou um efeito significativo para as variáveis consideradas $\left(\mathrm{X}^{2}(5)=13,15\right.$ e $\left.\mathrm{p}<0,02\right)$, evidenciando que a interpretação das proformas é influenciada por fatores semânticos. Daí que a preferência pela interpretação da proforma como correferente ao antecedente em todas as condiçôes, sugere que elas são interpretadas após o movimento, quando os antecedentes estão disponíveis à correferência, conforme a hipótese inicial postulada. Essa preferência se deu independentemente do tipo de elemento correferencial envolvido, uma vez que o teste qui-quadrado não revelou efeitos significativos quando se considerou apenas o tipo de retomada envolvido $\left(\left(\mathrm{X}^{2}(1)=0,03\right.\right.$ e p $\left.<0,85\right)$, conforme o indicado no gráfico 4 abaixo. Contudo, ao se analisar a variável tipo de frase em isolado, constatou-se um efeito significativo para essa variável, corroborando assim a afirmação, já vista na análise dos tempos de resposta, de que o processamento dos princípios de ligação é sensível a fatores semânticos $\left(\left(\mathrm{X}^{2}(2)=7,02\right.\right.$ e p < 0,02). O Gráfico 5 a seguir expóe os resultados dessa variável. 


\section{Gráfico 4}

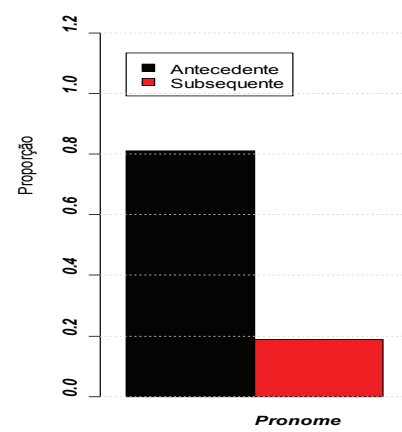

Gráfico da Tabela Cruzada

\section{Gráfico 5}
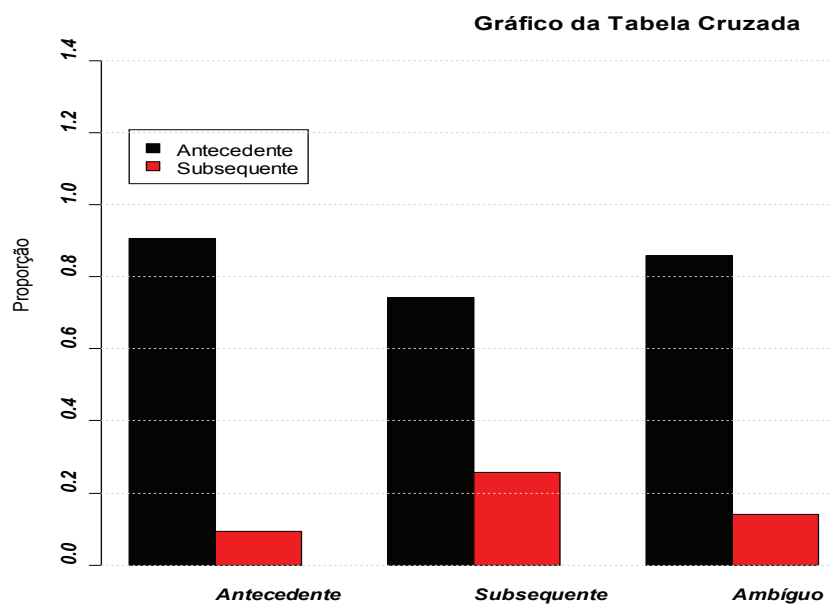

\section{Conclusões}

No que se refere aos princípios de ligação, parece haver uma convergência entre o modelo formal de computação linguística e as teorias de processamento, na medida em que o local preferencial para a açáo dos princípios definido no modelo formal corresponde à posição da retomada no momento do processamento. Isso significa que tão logo a proforma seja processada e haja um antecedente disponível, os princípios de ligação atuariam, o que aponta 
para a proposta de Nicol \& Swinney (1989). A franca preferência pela ligação com o antecedente, em detrimento da correferência com o subsequente, parece evidenciar ainda mais essa hipótese.

Não há diferença de custo procedimental entre os princípios. Todos parecem impor a mesma demanda de processamento. Entretanto, estão sujeitos a fatores externos ao sistema computacional, o que equivale a dizer que a sua atuaçâo é apenas em parte independente. Fatores semânticos e/ou contextuais podem influir no processamento, mesmo não sendo os fatores primordiais. Esses continuam sendo os sintático-estruturais, responsáveis pelo licenciamento de sentenças gramaticais.

Para dar conta da questão do movimento, uma análise possível é postular que haja uma derivação bottom-up para os TP's matriz e encaixado paralela a uma derivação top-down do constituinte WH-, sendo que a ação dos princípios se daria táo logo o constituinte WH- seja concatenado ao TP matriz, conforme o previsto por um modelo integrado de computação linguística (CORRÊA \& AUGUSTO, 2006). Essa solução, contudo, ainda carece de maiores evidências empíricas, constituindo-se, no estado atual das pesquisas sobre o processamento dos binding principles, em uma promissora abordagem.

Para tanto, é preciso ampliar as análises empreendidas no âmbito do presente estudo. Uma análise dos tempos de resposta dos segmentos posteriores ao crítico, em busca de possíveis efeitos spill-over afigura-se como uma quase necessidade, na medida em que a literatura em processamento correferencial é bastante pródiga em revelar efeitos que só se manifestam após um determinado ponto da sequência linguística que está sendo processada. Além disso, uma análise dos tempos de resposta à pergunta pode ser igualmente interessante, para evidenciar possíveis dificuldades na interpretaçáo das sentenças-teste. A manipulação de variáveis, como a posição do constituinte WH-, com sentenças com constituinte movido/não-movido, visando checar custo de processamento dos dois tipos de sentença, com e sem movimento, é também prevista na continuidade do trabalho. Novos testes, tais como um julgamento imediato de gramaticalidade, embutido na mesma tarefa experimental, pode evidenciar possíveis violaçóes dos princípios e o seu custo de processamento. Por fim, manipular contextos prévios os quais também possam atuar como fatores semânticos que influenciem a interpretação dos elementos correferenciais pode reforçar o papel dos fatores semânticos no processamento dos princípios de ligação. 


\section{Agradecimentos}

Meus agradecimentos à organização do III Workshop de Processamento Anafórico (III WPA), ocasião em que esses resultados puderam ser mostrados e discutidos pela primeira vez, recebendo úteis e valiosas contribuiçóes de todos os presentes, a quem também dirijo meus agradecimentos. Minha gratidão para os alunos do Curso de Psicopedagogia da UFPB, que gentilmente se dispuseram a atuar como sujeitos dessa pesquisa, e para meus alunos do curso de Letras, que em muito contribuíram durante a aplicação dos testes experimentais.

\section{Referências}

BADECKER, W.; STRAUB, K. The processing role of structural constraints on the interpretation of pronouns and anaphors. Journal of Experimental Psychology: Learning, Memory, and Cognition, 2002.

CHOMSKY, N. Lectures on government and binding. Dordrecht: Foris, 1981. . The Minimalist Program. Cambridge: MIT Press, 1995.

FERREIRA, M. Uma observação sobre o lugar da teoria da ligação e do critério temático dentro do Programa Minimalista. D.E.L.T.A., 16.1, 139-48

HORNSTEIN, N.; NUNES, J.; GROHMANN, K. Understanding Minimalism. Cambridge: CUP, 2005.

KENNISON, S. Comprehending the pronouns her, him, and his: implications for theories of referential processing. Journal of Memory and Language, 2003.

LEITÃO, M.; PEIXOTO, P.; SANTOS, S. Processamento da correferência intra-sentencial em português brasileiro. Veredas on-line, 2008.

; MELO, M. F. B. de. Processamento da Correferência Intersentencial. In: CAVALCANTE, M.; FARIA, E. M. B.; . Aquisição da Linguagem e Processamento Linguístico: Perspectivas Teóricas e Aplicadas. João Pessoa: EDUFPB, 2011.

MIOTO, C; SILVA, M. C.; VASCONCELLOS, R. Novo Manual de Sintaxe. Florianópolis: Insular, 4a ed.., 2010.

NICOL, J.; SWINNEY, D. The role of structure in coreference assignment during sentence comprehension. Journal of Psycholinguistic Research, 1989. p. $5-20$. 
OLIVEIRA, Rosana; LEITÃO, Márcio M.; ARAÚJO, Elioenai. A Influência dos Antecedentes Vinculados e não vinculados no processamento da anáfora "ele(a) mesmo(a)". Revista do GELNE, Grupo de Estudos Linguísticos do Nordeste, v. 5, n. 1 e 2, Natal: UFRN, 2013, p. 115-134. ISSN Versão Digital: 2236-0883 | ISSN Versão Impressa: 1517-7874. ; ; HENRIQUE, Judithe. A Influência dos Antecedentes Vinculados e náo vinculados no processamento da anáfora "a si mesmo(a)". Linguística, v. 8, n. 2, 2012, p. 115-134. ISSN Versão Digital: 2238-975-X | ISSN Versão Impressa: 1808-835-X.

STURT, P. The time-course of the application of binding constraints in reference resolution. Journal of Memory and Language, 2003.

\title{
MINIMALISM IN A PSYCHOLINGUISTIC POINT OF VIEW: BINDING PRINCIPLES AND ITS OPERATION IN ON-LINE PROCESSING OF COREFERENCE
}

\begin{abstract}
:
This article aims to evaluate how much a formal model of Grammar can be apply to on-line mental processes that underlying the sentential processing. For this intent, it was carried on an experiment in which it was observed how the Binding Principles act in the processing of correferential relations in Brazilian Portuguese (BP). The results suggest that there is a convergence between linguistic computation and theories about linguistic processing.
\end{abstract}

KEYWORDS: coreference; binding principles; linguistic processing.

Recebido em 30/03/14 Aprovado em 30/05/14 